NASA TECHNICAL NOTE

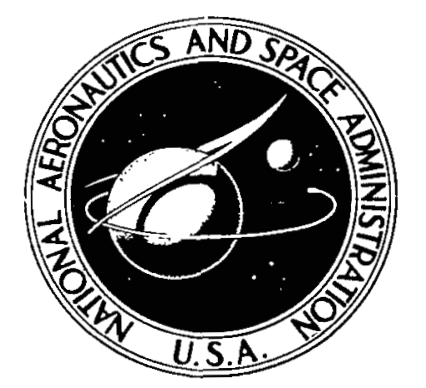

NASA TN D-6371.

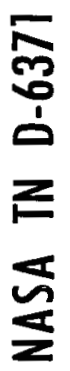
C.I

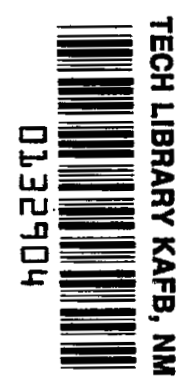

LOAN COPY: RETURN TO AFWL (DOGL) KIRTLAND AFB, N. M.

\title{
OPTIMIZATION OF CONICAL HYDROSTATIC BEARING FOR MINIMUM FRICTION
}

by Lester J. Nypan, Bernard J. Hamrock, Herbert W. Scibbe, and William J. Anderson Lewis Research Center Cleveland, Obio 44135

NATIONAL aERONAUTICS AND SPACE ADMINISTRATION - WASHINGTON, D. CÚNE 19 II 
1. Report No.

NASA TN D-6371

4. Title and Subtitle

OPTIMIZATION OF CONICAL HYDROSTATIC BEARING FOR MINIMUM FRICTION

7. Author(s) Lester J. Nypan, Bernard J. Hamrock, Herbert W. Scibbe, and William J. Anderson

9. Performing Organization Name and Address

2. Government Accession No.

3. Recipient's Catalog No.

5. Report Date June 1971

6. Performing Organization Code

8. Performing Organization Report No. E-6101

10. Work Unit No. 126-15

Lewis Research Center

National Aeronautics and Space Administration

Cleveland, Ohio 44135

12. Sponsoring Agency Name and Address

National Aeronautics and Space Administration

Washington, D.C. 20546

15. Supplementary Notes

16. Abstract

Equations for the flow rate, load capacity, and friction torque for a conical hydrostatic bearing were developed. These equations were solved by a digital computer program to determine bearing configurations for minimum friction torque. Design curves are presented. Results are shown for both laminar and turbulent flow conditions.

17. Key Words (Suggested by Author(s)) Conical hydrostatic bearing Optimization design

19. Security Classif. (of this report) Unclassified

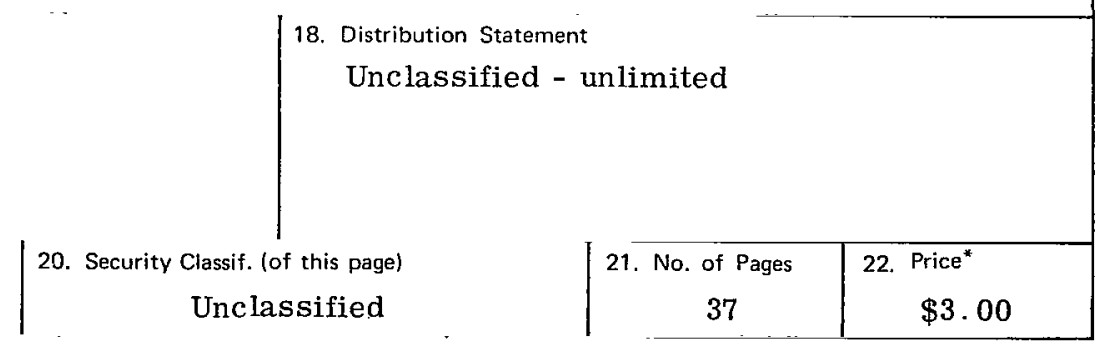




\title{
OPTIMIZATION OF CONICAL HYDROSTATIC BEARING
}

\author{
FOR MINIMUM FRICTION \\ by Lester J. Nypan,* Bernard J. Hamrock, Herbert W. Scibbe, \\ and William J. Anderson \\ Lewis Research Center
}

\section{SUMMARY}

Equations for the flow rate, load capacity, and friction torque for a conical hydrostatic bearing were developed. These equations were solved by a digital computer program to determine bearing configurations for minimum friction torque. Design curves are presented that show optimal bearing dimensions or minimum friction torque as a function of dimensionless flow rate for a range of dimensionless load capacity. Results are shown for both laminar and turbulent flow conditions.

The results indicate that hydrostatic pocket friction is a significant portion of the total friction torque. However, the bearing dimensions for a minimum friction design are affected very little by inclusion of pocket friction in the analysis. For laminar flow the values of the outer-land radius ratio $x_{3}$ and outer bearing radius ratio $x_{4}$ did not change significantly with increasing friction factor. For turbulent flow, the outer bearing radius ratio $\mathrm{x}_{4}$ did not change with increasing friction factor; therefore, the value determined for $\mathrm{X}_{4}$ in the laminar flow case is valid for all turbulent flows.

\section{INTRODUCTION}

The design of incompressible fluid hydrostatic bearings with a variety of bearing configurations has been treated by Rippel (ref. 1) and others (refs. 2 and 3). These analyses have resulted in equations for load capacity, flow rate, and friction torque. References 1 and 2 also indicate optimum bearing proportions to minimize pressurization or pumping power requirements of such bearings. Preliminary studies on combination rolling-element - fluid-film bearings for high-speed applications such as the hybrid

* Professor of Engineering, San Fernando Valley State College, Northridge, California; NASA Summer Faculty Fellow in 1970. 
boost bearing (ref. 4) or the series hybrid fluid-film - rolling-element bearing (ref. 5) have led to an interest in the design and performance characteristics of a conical hydrostatic bearing optimized to minimize bearing friction torque.

The series hybrid bearing requires a minimum-friction fluid-film bearing in order to obtain the maximum reduction in rotative speed for the rolling-element bearing. The conical hydrostatic bearing was selected for analysis as it has both thrust and radial load capacity without the complexity of separate thrust and journal bearings. Overall film thickness and friction torque of the bearing may be readily modified by changing the supply pressure or, equivalently, the flow rate. This feature makes the conical hydrostatic bearing a prime candidate for use in future experimental work on the series hybrid bearing concept.

This study presents an analysis of a conical hydrostatic bearing optimized to minimize friction and a method of designing such a bearing for various combinations of operating conditions of load capacity, flow rate, and Reynolds number.

Two operating regimes may be identified as of interest in conical hydrostatic bearing design. These are (1) the low- and moderate-speed regime, where laminar flow may be expected under the lands and within the hydrostatic pockets, and (2) the highspeed regime, where turbulent flow might be expected within the hydrostatic pockets.

The method used to predict bearing performance characteristics in each of these cases will be that of expressing equations relating pressure, thrust load, flow, and friction torque in terms of bearing design parameters. Friction torque can then be minimized by equating the rate of change of friction torque with bearing size to zero.

\section{ANALYSIS}

Figure 1 shows the configuration of a conical hydrostatic bearing as applied to a series hybrid fluid-film - rolling-element bearing. Figure 2 shows the type of conical hydrostatic bearing considered for this design application. Fluid is introduced at the shaft centerline (fig. 2(a)) and is fed radially to orifice or capillary flow restrictors, at radius $R_{0}$, which provide pressure compensation for potential misalinement and varying loads. The hydrostatic pressure available for load capacity is that developed at radius $R_{0}$ because of centrifugal effects. After the fluid has passed through the compensating element, a pressure $\mathrm{p}$ is presumed to be available in the hydrostatic pockets to resist a thrust load F. (Symbols are defined in appendix A.) The required pressure area is determined by the thrust load the bearing must carry at supply pressure $p$. The load capacíty can be expressed by

$$
\mathrm{F}=\frac{\mathrm{p} \pi}{2}\left(\mathrm{R}_{4}^{2}+\mathrm{R}_{3}^{2}-\mathrm{R}_{2}^{2}-\mathrm{R}_{1}^{2}\right)
$$


Equation (1) presumes that the full pressure $\mathrm{p}$ acts over the area of the pockets and that the average pressure over the circumferential lands is $p / 2$. This is a good approximation provided that $R_{4} / R_{3}$ and $R_{2} / R_{1}$ are not too much greater than 1 . The effects of relative motion on pressure profiles are neglected in this analysis.

Flow will take place radially over each circumferential land. The total flow is the sum of the flow over the lands or

$$
\mathbf{Q}=\mathbf{Q}_{\mathrm{i}}+\mathbf{Q}_{\mathrm{O}}=\frac{\pi \mathrm{h}_{\mathrm{L}}^{3} \mathrm{p} \sin \theta}{6 \mu}\left(\frac{1}{\ln \frac{\mathbf{R}_{2}}{\mathbf{R}_{1}}}+\frac{1}{\ln \frac{\mathbf{R}_{4}}{\mathrm{R}_{3}}}\right)
$$

The derivation of this equation is shown in appendix $B$.

Friction torque due to the circumferential lands is presumed to be the result of laminar shearing of the fluid between inner and outer circumferential lands and the mating surface. The friction torque due to the inner and outer circumferential lands can be written as

$$
\mathbf{M}_{\mathrm{L}}=\frac{\pi \mu \omega_{\mathrm{f}}}{2 \mathrm{~h}_{\mathrm{L}} \sin \theta}\left(\mathrm{R}_{4}^{4}-\mathrm{R}_{3}^{4}+\mathrm{R}_{2}^{4}-\mathrm{R}_{1}^{4}\right)
$$

The derivation of this equation is also shown in appendix $B$.

Let

$$
\begin{array}{ll}
\mathrm{X}_{2}=\frac{\mathrm{R}_{2}}{\mathrm{R}_{1}} & \overline{\mathrm{F}}=\frac{2 \mathrm{~F}}{\pi \mathrm{pR} \mathrm{R}_{1}^{2}} \\
\mathrm{X}_{3}=\frac{\mathrm{R}_{3}}{\mathrm{R}_{1}} & \overline{\mathrm{Q}}=\frac{6 \mu \mathrm{Q}}{\pi \mathrm{ph} \mathrm{L}_{\mathrm{L}}^{3} \sin \theta} \\
\mathrm{X}_{4}=\frac{\mathrm{R}_{4}}{\mathrm{R}_{1}} & \overline{\mathrm{M}}_{\mathrm{L}}=\frac{2 \mathrm{M}_{\mathrm{L}} \mathrm{h}_{\mathrm{L}} \sin \theta}{\pi \mu \omega_{\mathrm{f}} \mathrm{R}_{1}^{4}}
\end{array}
$$

equations (1) to (3) can be written in dimensionless form as

$$
\overline{\mathrm{F}}=\mathrm{X}_{4}^{2}+\mathrm{x}_{3}^{2}-\mathrm{x}_{2}^{2}-1
$$




$$
\begin{aligned}
& \overline{\mathrm{Q}}=\overline{\mathrm{Q}}_{\mathrm{i}}+\overline{\mathrm{Q}}_{\mathrm{O}}=\frac{1}{\ln \mathrm{X}_{2}}+\frac{1}{\ln \frac{\mathrm{X}_{4}}{\mathrm{X}_{3}}} \\
& \overline{\mathrm{M}}_{\mathrm{L}}=\mathrm{X}_{4}^{4}-\mathrm{X}_{3}^{4}+\mathrm{X}_{2}^{4}-1
\end{aligned}
$$

Solving for $\mathrm{x}_{4}$ in equation (5) gives

$$
\mathrm{X}_{4}=\mathrm{X}_{3} \exp \left(\frac{1}{\overline{\mathrm{Q}}-\frac{1}{\ln \mathrm{X}_{2}}}\right)
$$

Note that $\mathrm{X}_{4}$ is undefined for $\overline{\mathrm{Q}}=1 / \ln \mathrm{X}_{2}$. Substituting equation (7) for $\mathrm{X}_{4}$ into equations (4) and (6) gives

$$
\begin{aligned}
\overline{\mathrm{F}} & =\mathrm{X}_{3}^{2}\left[1+\exp \left(\frac{2}{\overline{\mathrm{Q}}-\frac{1}{\ln \mathrm{X}_{2}}}\right)\right]-\mathrm{x}_{2}^{2}-1 \\
\overline{\mathrm{M}}_{\mathrm{L}} & =\mathrm{X}_{3}^{4}\left[-1+\exp \left(\frac{4}{\overline{\mathrm{Q}}-\frac{1}{\ln \mathrm{X}_{2}}}\right)\right]+\mathrm{x}_{2}^{4}-1
\end{aligned}
$$

Solving for $\mathrm{X}_{3}$ in equation (8) gives

$$
\mathrm{X}_{3}=\left[\frac{\overline{\mathrm{F}}+\mathrm{X}_{2}^{2}+1}{1+\exp \left(\frac{2}{\overline{\mathrm{Q}}-\frac{1}{\ln \mathrm{X}_{2}}}\right)}\right]^{1 / 2}
$$


Substituting equation (10) into equation (9) results in

$$
\begin{gathered}
\overline{\mathrm{M}}_{\mathrm{L}}=\mathrm{x}_{2}^{4}+\left(\overline{\mathrm{F}}+\mathrm{x}_{2}^{2}+1\right)^{2} \tanh \left(\frac{1}{\overline{\mathrm{Q}}-\frac{1}{\ln \mathrm{X}_{2}}}\right)-1 \\
\frac{\mathrm{d}_{\mathrm{M}} \mathrm{L}}{\mathrm{d \textrm {X } _ { 2 }}}=4 \mathrm{x}_{2}^{3}+\left(\overline{\mathrm{F}}+\mathrm{X}_{2}^{2}+1\right)\left[4 \mathrm{X}_{2} \tanh \left(\frac{1}{\overline{\mathrm{Q}}-\frac{1}{\ln \mathrm{X}_{2}}}\right)-\frac{\left(\overline{\mathrm{F}}+\mathrm{X}_{2}^{2}+1\right)}{\left.\mathrm{x}_{2} \overline{(\bar{Q}} \ln \mathrm{X}_{2}-1\right)^{2}} \operatorname{sech}^{2}\left(\frac{1}{\overline{\mathrm{Q}}-\frac{1}{\ln \mathrm{X}_{2}}}\right)\right]
\end{gathered}
$$

\section{Physical Restrictions}

From figure 2 and the relations for the dimensionless radii, the following can be written:

$$
1<\mathrm{x}_{2}<\mathrm{x}_{3}<\mathrm{x}_{4}
$$

From equation (10) and inequality (13),

$$
\mathrm{X}_{2}<\left[\frac{\overline{\mathrm{F}}+\mathrm{x}_{2}^{2}+1}{1+\exp \left(\frac{2}{\bar{Q}-\frac{1}{\ln \mathrm{x}_{2}}}\right)}\right]^{1 / 2}
$$

A further restriction which one needs in order to get reasonable results is that

$$
\overline{\mathrm{Q}}_{\mathrm{O}} \geq \overline{\mathrm{Q}}_{\mathrm{i}} \rightarrow \frac{1}{\ln \frac{\mathrm{X}_{4}}{\mathrm{X}_{3}}}>\frac{1}{\ln \mathrm{X}_{2}} \rightarrow \frac{\mathrm{X}_{4}}{\mathrm{X}_{3}}<\mathrm{X}_{2}
$$


Making use of equation (10), inequality (15) yields

$$
\mathrm{X}_{2}>\exp \left(\frac{2}{\overline{\mathrm{Q}}}\right)
$$

Making use of equations (14) and (16) while letting $\mathrm{X}_{2} \rightarrow \exp \left(\frac{2}{\overline{\mathrm{Q}}}\right)$ yields

$$
\mathrm{e}^{2 / \overline{\mathrm{Q}}}<\left(\frac{\overline{\mathrm{F}}+\mathrm{e}^{4 / \bar{Q}}+1}{1+\mathrm{e}^{4 / \bar{Q}}}\right)^{1 / 2}
$$

The preceding results in the following relation between $\overline{\mathrm{F}}$ and $\overline{\mathrm{Q}}$ :

$$
\overline{\mathrm{F}}>\exp \left(\frac{8}{\overline{\mathrm{Q}}}\right)-1
$$

\section{Low-Speed Operating Regime}

At low speeds pocket friction will occur through laminar shearing of the fluid. The pressure gradient created by the action of the radial lands and pockets will also contribute to friction torque, as has been shown by Shinkle and Hornung (ref. 6). Their experimental results, the envelope of which is reproduced in figure 3 , supports their analytical finding that the effective friction shear stress may be calculated from $\mathrm{f}=2 \tau / \rho V^{2}$ with $\mathrm{f}=8 / \mathrm{Re}$ in the laminar flow regime $(\operatorname{Re}<1000)$. For the conical hydrostatic bearing, $\operatorname{Re}=\rho r \omega_{\mathrm{f}} \mathrm{h}_{\mathrm{p}} / \mu$ and

$$
\tau=\frac{4 \mu}{{ }^{h_{\mathrm{P}}}} \mathrm{r} \omega_{\mathrm{f}}
$$

Then

$$
M_{P}=\int_{R_{2}}^{R_{3}} r \tau d A=\int_{R_{2}}^{R_{3}} r\left(\frac{4 \mu r \omega_{f}}{h_{P}}\right) f_{r}\left(\frac{2 \pi r d r}{\sin \theta}\right)
$$

or

$$
M_{P}=\frac{2 \pi \mu \omega_{f^{f} r}}{h_{P} \sin \theta}\left(R_{3}^{4}-R_{2}^{4}\right)
$$


The total fluid-film friction torque is the sum of the friction torque due to the circumferential lands and the pocket friction. This can be expressed as

$$
\mathbf{M}_{t}=\mathbf{M}_{L}+\mathbf{M}_{\mathbf{P}}
$$

By use of equation (19), equation (20) can be written in dimensionless form as

$$
\overline{\mathrm{M}}_{\mathrm{t}}=\frac{2 \mathrm{M}_{\mathrm{t}} \mathrm{h}_{\mathrm{L}} \sin \theta}{\pi \mu \omega_{\mathrm{f}} \mathrm{R}_{1}^{4}}=\overline{\mathrm{M}}_{\mathrm{L}}+\mathrm{C}_{1}\left(\mathrm{x}_{3}^{4}-\mathrm{x}_{2}^{4}\right)
$$

where

$$
\mathrm{C}_{1}=4 \mathrm{f}_{\mathrm{r}} \frac{\mathrm{h}_{\mathrm{L}}}{\mathrm{h}_{\mathbf{P}}}
$$

In bearings where friction is to be minimized, the fraction of potential pocket area actually used as hydrostatic pockets $\mathrm{f}_{\mathrm{r}}$ will be close to unity. It may then be noted that, for $\mathrm{h}_{\mathrm{P}}>>\mathrm{h}_{\mathrm{L}}, \mathrm{C}_{1} \cong 0$ and in equation (21) the total friction torque becomes equal to that due to the circumferential lands $\left(\overline{\mathrm{M}}_{\mathrm{t}}=\overline{\mathrm{M}}_{\mathrm{L}}\right)$.

Differentiating equation (21) with respect to $\mathrm{x}_{2}$ results in

$$
\frac{\mathrm{d}_{\mathrm{M}}}{\mathrm{dX}_{2}}=\frac{\mathrm{d} \overline{\mathrm{M}}_{\mathrm{L}}}{\mathrm{d \textrm {X } _ { 2 }}}+4 \mathrm{C}_{1}\left(\mathrm{x}_{3}^{3} \frac{\mathrm{dx}_{3}}{\mathrm{dx_{2 }}}-\mathrm{x}_{2}^{3}\right)
$$

The expression for $\mathrm{dX}_{3} / \mathrm{dx}_{2}$ can be obtained from equation (10) as

$\frac{\mathrm{dx}_{3}}{\mathrm{dx}_{2}}=\frac{1}{\mathrm{x}_{3}}\left\{\frac{\mathrm{x}_{2}}{\left.1+\exp \left(\frac{2}{\left.\overline{\mathrm{Q}}-\frac{1}{\ln \mathrm{X}_{2}}\right)}\right) \mathrm{x}_{2}^{2}+1\right) \exp \left(\frac{2}{\left.\overline{\mathrm{Q}}-\frac{1}{\ln \mathrm{X}_{2}}\right)}\right)}\right\}$ 
Therefore, with equations (10), (12), and (24), equations (21) and (23) are expressed in terms of $C_{1}, x_{2}, \bar{F}$, and $\bar{Q}$.

\section{High-Speed Regime}

When speeds become large enough to result in Reynolds numbers $\left(\operatorname{Re}=\rho \omega_{\mathrm{f}} \mathrm{R}_{1} \mathrm{~h}_{\mathrm{L}} / \mu\right)$ greater than 1000, the turbulent friction action of the hydrostatic pockets must be included.

Bearings operating within the turbulent flow regime have been treated by a number of investigators (refs. 7 to 9). The work of Hirs (ref. 9), however, most accurately represents the experimental work of Shinkle and Hornung (ref. 6) on turbulent hydrostatic bearing friction measurements.

Figure 3 shows the envelope of Shinkle and Hornung's experimental data for hydrostatic journal bearing pockets with 0.53 - to 8.16 -millimeter (0.021-to 0.321-in.) depth. The figure shows friction factor $\left(\mathrm{f}=2 \tau / \rho \mathrm{V}^{2}\right)$ as a function of Reynolds number (Re $=$ $\rho \mathrm{Vh} / \mu)$. The friction factor recommended by Hirs $\left(f=0.062 \operatorname{Re}^{-0.25}\right)$ is also shown in figure 3 . This function is used to predict conical hydrostatic pocket friction stress,

$$
\tau=0.031 \rho \mathrm{V}^{2} \operatorname{Re}^{-0.25}
$$

From equation (25), the friction torque due to the hydrostatic pockets $M_{\mathbf{P}}$ can be calculated by

$$
M_{P}=\int_{R_{2}}^{R_{3}} r(0.031) \rho V^{2}\left(\frac{\rho r \omega_{f} h_{P}}{\mu}\right)^{-0.25} f_{r}\left(\frac{2 \pi r d r}{\sin \theta}\right)
$$

or

$$
\mathrm{M}_{\mathrm{P}}=\frac{(0.031) 2 \pi \mathrm{f}_{\mathrm{r}}}{4.75 \sin \theta} p^{0.75} \omega_{\mathrm{f}}^{1.75}\left(\frac{\mu}{\mathrm{h}_{\mathrm{P}}}\right)^{0.25}\left(\mathrm{R}_{3}^{4.75}-\mathrm{R}_{2}^{4.75}\right)
$$

The total friction torque, taking into account turbulence, can be expressed by equation (20), where ${ }^{M_{P}}$ is now defined by equation (27). The dimensionless form of the 
total friction torque for turbulent conditions may be expressed as

$$
\bar{M}_{t}=\frac{2 M_{t} \sin \theta h_{L}}{\pi \mu \omega_{f} R_{1}^{4}}=\bar{M}_{L}+C_{2}\left(x_{3}^{4.75}-x_{2}^{4.75}\right)
$$

where

$$
\mathrm{C}_{2}=\frac{2(0.062)}{4.75} \mathrm{f}_{\mathrm{r}}\left(\frac{\rho \mathrm{R}_{1} \omega_{\mathrm{f}} \mathrm{h}_{\mathrm{P}}}{\mu}\right)^{0.75} \frac{\mathrm{h}_{\mathrm{L}}}{\mathrm{h}_{\mathrm{P}}}
$$

Differentiating equation (28) with respect to $\mathrm{x}_{2}$ gives

$$
\frac{\mathrm{d}_{\mathrm{M}}}{\mathrm{dX}_{2}}=\frac{\mathrm{d}_{\mathrm{M}} \mathrm{L}}{\mathrm{dx}_{2}}+4.75 \mathrm{C}_{2}\left(\mathrm{x}_{3}^{3.75} \frac{\mathrm{dx}_{3}}{\mathrm{dX}_{2}}-\mathrm{x}_{2}^{3.75}\right)
$$

Therefore, with equations (10), (12), and (24), equations (28) and (30) can be expressed in terms of $\mathrm{C}_{2}, \mathrm{x}_{2}, \overline{\mathrm{F}}$, and $\overline{\mathrm{Q}}$.

\section{Optimization Procedure}

The equations (10), (11), (12), (21), (23), (24), (28), and (30) developed in the analysis were programmed on a digital computer. It is seen from these equations that the friction torque $\overline{\mathrm{M}}_{\mathrm{t}}$ and its derivative with respect to $\mathrm{X}_{2}$ are functions of the dimensionless flow rate $\bar{Q}$, the dimensionless load capacity $\bar{F}$, the dimensionless coefficient $C_{1}$ or $\mathrm{C}_{2}$ (depending on whether the bearing is operating in the laminar or turbulent regime), and the ratio of the outer radius to the inner radius of the inner land $\mathrm{x}_{2}$.

The problem as defined in the INTRODUCTION is to find the optimal conical hydrostatic bearing configuration for minimum friction torque for laminar and turbulent flow conditions. This means setting $d \overline{\mathbf{M}}_{t} / d x_{2}$ equal to zero in equations (23) and (30) and finding the values of $\mathrm{X}_{2}$ which satisfy these equations. The "false position" numerical method was used in finding the optimal value of $x_{2}$. When $C_{1}$ or $C_{2}, \bar{F}$, and $\bar{Q}$ are known, the optimal values of $\mathrm{X}_{2}$ for minimal friction could be obtained for laminar or turbulent flow conditions. 


\section{DISCUSSION OF RESULTS}

The results are shown in figures 4 to 22 . In all these figures the abscissa is the dimensionless flow rate $\bar{Q}$, and for each figure seven curves are shown representing seven values $(0.5,1,2,3,5,7$, and 10$)$ of dimensionless load capacity $\overline{\mathbf{F}}$. On the ordinate of these figures, the optimal bearing configuration or the resulting minimum friction torque is given. For low-speed operation, or when laminar flow exists, the results are shown in figures 4 to 13 , where $\mathrm{C}_{1}=0,0.2,0.4$, or 0.8 . For high-speed operation, when turbulent flow exists, the results are shown in figures 14 to 22 , where $\mathrm{C}_{2}=0.2,0.4$, or 0.8 . The values of $\overline{\mathrm{F}}$ and $\overline{\mathrm{Q}}$ were chosen such that they satisfy inequality (13). The following comments can be made about figures 4 to 22 :

(1) A designer is able to find optimal bearing configurations $\left(x_{2}, x_{3}\right.$, and $\left.x_{4}\right)$ for minimum friction torque given the flow rate, load, and angular velocity.

(2) In figures $5,15,18$, and 21, it is seen that $\mathrm{x}_{3}$ approaches an asymptote rather quickly. Furthermore, the asymptotic values of $\mathrm{x}_{4}$ in figure 6 are exactly the asymptotic values of $\mathrm{X}_{3}$ in figure 5 for a given dimensionless load capacity.

(3) For all the laminar flow cases $\left(C_{1}=0,0.2,0.4\right.$, and 0.8$)$, it was found that the values of $\mathrm{X}_{3}$ and $\mathrm{X}_{4}$ did not change significantly when $\mathrm{C}_{1}$ changed. Therefore, figures 5 and 6 , which are plotted for a $C_{1}=0$, are to be used in obtaining the values of $\mathrm{X}_{3}$ and $\mathrm{X}_{4}$, respectively, as long as the pocket flow is laminar (Re $\left.<1000\right)$.

(4) For all the turbulent flow cases $\left(C_{2}=0.2,0.4\right.$, and 0.8$)$, it was found that $x_{4}$ did not change with change of $C_{2}$. Therefore, figure 6 may be used in obtaining the value of $\mathrm{X}_{4}$.

(5) It was found that the addition of the laminar or turbulent pocket friction term in the friction torque expression did not appreciably change the bearing dimensions (values of $\mathrm{X}_{2}, \mathrm{X}_{3}$, and $\mathrm{x}_{4}$ ) for minimum torque. It seems that, no matter how much $\mathrm{C}_{1}$ and $\mathrm{C}_{2}$ are increased (within reasonable limits), torque is still less for pocket areas than for the land areas.

(6) Friction torque values rise substantially when the laminar and turbulent pocket friction terms are included, as can be seen from comparing figure 7 with figures 9,11 , and 13 and with figures 16,19 , and 22 . The torque increase is greatest at high flow rates.

\section{SUMMARY OF RESULTS}

Equations for the flow rate, load capacity, and friction torque for a conical hydrostatic bearing were developed. A digital computer program was developed which determined the optimal bearing configuration for minimum friction torque. Design curves 
showing optimal bearing configurations (radius ratios $\mathrm{x}_{2}, \mathrm{x}_{3}$, and $\mathrm{x}_{4}$ ) or minimum friction torque as a function of dimensionless flow rate were plotted for seven values of dimensionless load capacity. Design curves were shown for both laminar and turbulent flow conditions. The following results were obtained:

1. Friction torque was strongly affected by hydrostatic pocket friction; however, bearing dimensions for a minimum friction design were affected very little by pocket friction.

2. For all laminar-flow cases, the values of $x_{3}$ and $x_{4}$ did not change significantly with increasing values of friction factor.

3. For all turbulent flow cases, $x_{4}$ did not change with increasing values of friction factor; therefore, the value of the friction factor, $\mathrm{C}_{1}=0$, determined for laminar flow may be used to obtain the value of $\mathrm{X}_{4}$ for all turbulent flows.

Lewis Research Center, National Aeronautics and Space Administration, Cleveland, Ohio, February 23, 1971, 126-15. 

$\omega_{f} \quad$ rotational speed of fluid-film bearing

Subscripts:

L land

P pocket 


\section{APPENDIX B}

\section{DERIVATION OF FLOW RATE AND FRICTION TORQUE EQUATIONS}

The pressure in the pocket is higher than that outside the bearing. Flow will take place through the clearance over the inner and outer lands (see fig. 2(b)). For laminar flow in a narrow slot,

$$
Q=-\frac{b h_{L}^{3}}{12 \mu} \frac{\mathrm{dp}}{\mathrm{dx}}
$$

where $\mathrm{x}$ is the distance along the slot.

For the geometry of figure 2, the following can be written for flow over the outer land:

$$
\begin{gathered}
\mathrm{dx}=\frac{\mathrm{dR}}{\sin \theta} \\
\mathrm{b}=2 \pi \mathrm{R} \\
\therefore \mathrm{Q}_{\mathrm{O}}=-\frac{\pi \mathrm{Rh}_{\mathrm{L}}^{3} \sin \theta}{6 \mu} \frac{\mathrm{dp}}{\mathrm{dR}}
\end{gathered}
$$

This may be integrated to yield

$$
\mathrm{Q}_{\mathrm{O}}=\frac{\pi \mathrm{h}_{\mathrm{L}}^{3} \sin \theta \mathrm{p}}{6 \mu} \frac{1}{\ln \frac{\mathrm{R}_{4}}{\mathrm{R}_{3}}}
$$

A similar expression can be developed for the flow over the inner land $Q_{i}$. The flow over both lands is

$$
\mathrm{Q}=\mathrm{Q}_{\mathrm{O}}+\mathrm{Q}_{\mathrm{i}}=\frac{\pi \mathrm{h}_{\mathrm{L}}^{3} \mathrm{p} \sin \theta}{6 \mu}\left(\frac{1}{\ln \frac{\mathrm{R}_{2}}{\mathrm{R}_{1}}}+\frac{1}{\ln \frac{\mathrm{R}_{4}}{\mathrm{R}_{3}}}\right)
$$


Friction torque is assumed due to laminar shearing of fluid over the lands, so that shear stress can be written as

$$
\tau=\frac{\mu \mathrm{V}}{\mathrm{h}_{\mathrm{L}}}
$$

Friction force at radius $R$ is $(2 \pi R d x) \mu\left(R \omega_{f}\right) / h_{L}$. The friction torque of the outer land is

$$
\mathbf{M}_{\mathrm{o}}=\int_{\mathbf{R}_{3}}^{\mathrm{R}_{4}} \frac{2 \pi \mu \omega_{\mathrm{f}}}{\mathrm{h}_{\mathrm{L}}} \mathrm{R}^{3} \frac{\mathrm{dR}}{\sin \theta}=\frac{\pi \mu \omega_{\mathrm{f}}}{2 \mathrm{~h}_{\mathrm{L}} \sin \theta}\left(\mathrm{R}_{4}^{4}-\mathrm{R}_{3}^{4}\right)
$$

The friction torque due to both lands can be written as

$$
\mathbf{M}_{\mathbf{L}}=\mathbf{M}_{\mathrm{i}}+\mathbf{M}_{\mathrm{o}}=\frac{\pi \mu \omega_{\mathrm{f}}}{2 \mathrm{~h}_{\mathrm{L}} \sin \theta}\left(\mathrm{R}_{4}^{4}-\mathrm{R}_{3}^{4}+\mathrm{R}_{2}^{4}-\mathrm{R}_{1}^{4}\right)
$$




\section{REFERENCES}

1. Rippel, H. C. : Cast Bronze Hydrostatic Bearing Design Manual. Cast Bronze Bearing Institute, Inc., Cleveland, Ohio.

2. Aston, R. L.; O'Donoghue, J. P. ; and Rowe, W. B.: Design of Conical Hydrostatic Journal Bearings. Mach. Prod. Eng., vol. 116, no. 2988, Feb. 18, 1970, pp. 250-254.

3. Elwell, R. C.; and Sternlicht, B.: Theoretical and Experimental Analysis of Hydrostatic Thrust Bearings. J. Basic Eng., vol. 82, no. 3, Sept. 1960, pp. 505-512.

4. Wilcock, Donald F.; and Winn, Leo W.: The Hybrid-Boost Bearing - A Method of Obtaining Long Life in Rolling Contact Bearing Applications. Paper 69-LUB-16, ASME, Oct. 1969.

5. Parker, Richard J.; Fleming, David P. ; Anderson, William J.; and Coe, Harold H. : Experimental Evaluation of the Series-Hybrid Rolling-Element Bearing. NASA TN D-7011, 1970.

6. Shinkle, J. N. ; and Hornung, K. G.: Frictional Characteristics of Liquid Hydrostatic Journal Bearings. J. Basic Eng., vol. 87, no. 1, Mar. 1965, pp. 163-169.

7. Elrod, H. G., Jr.; and Ng, C. W.: A Theory for Turbulent Fluid Films and Its Application to Bearings. J. Lubr. Tech., vol. 89, no. 3, July 1967, pp. 346-362.

8. Constantinescu, V. N.; and Galetuse, S.: On the Determination of Friction Forces in Turbulent Lubrication. ASLE Trans., vol. 8, no. 4, Oct. 1965, pp. 367-380.

9. Hirs, G. G. : Fundamentals of a Bulk-Flow Theory for Turbulent Lubricant Films. Doctorate Thesis, Delft Univ. of Tech., Delft, Netherlands, 1970. 


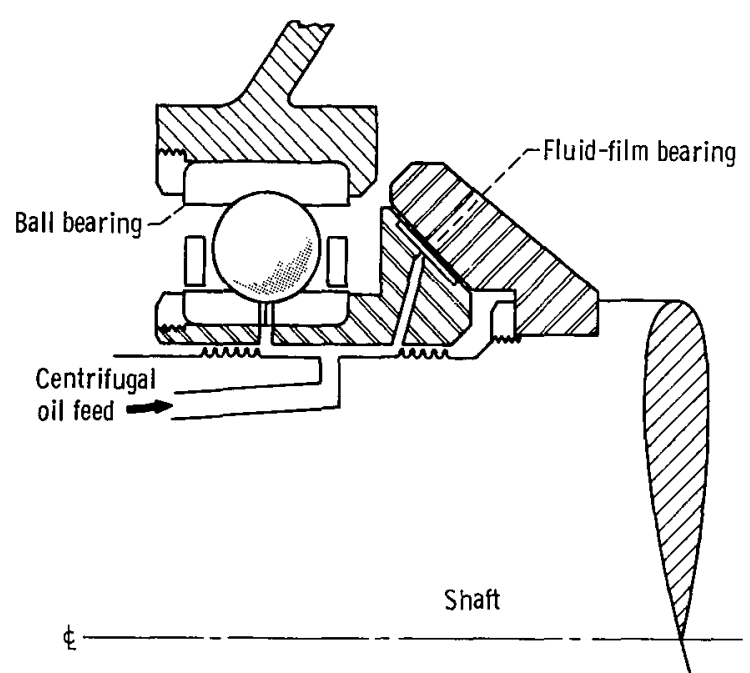

Figure 1. - Schematic diagram of series hybrid fluid-film - rollingelement bearing.
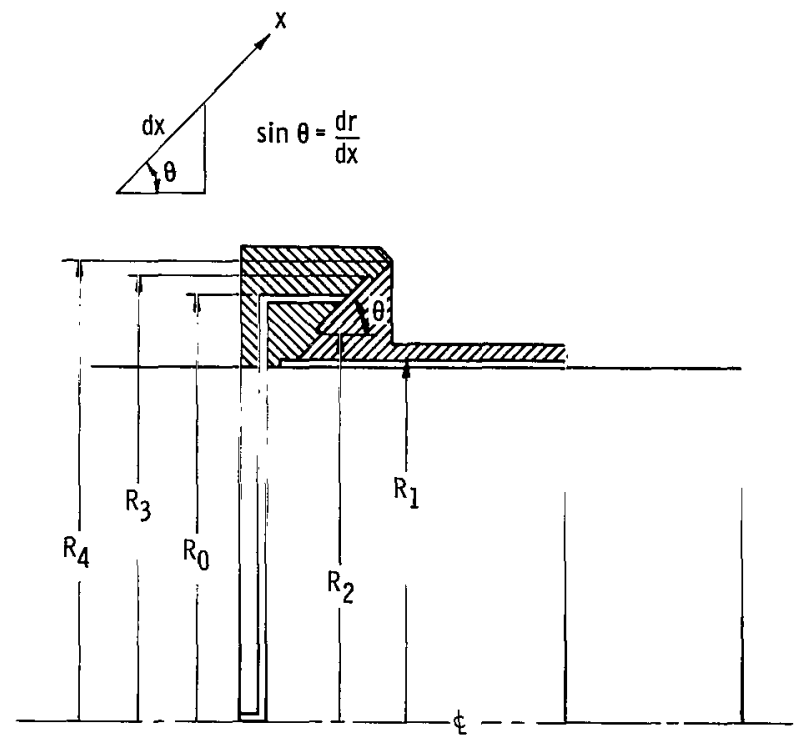

(a) Section view.

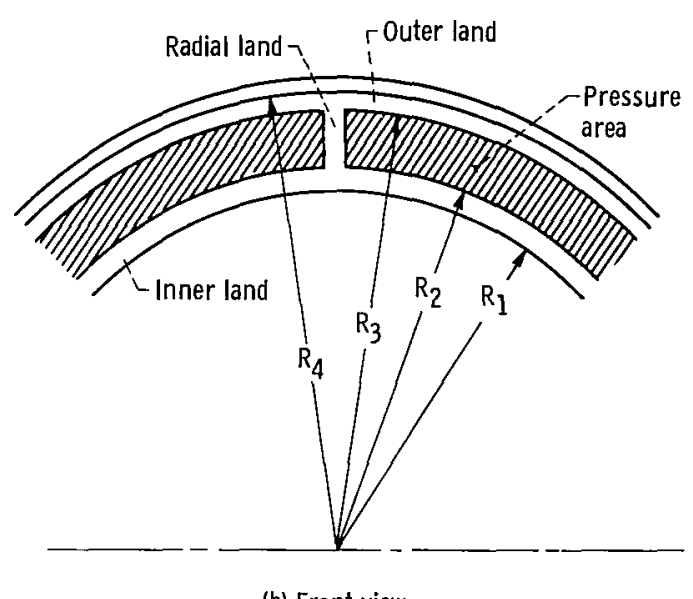

(b) Front view.

Figure 2. - Schematic diagrams of conical hydrostatic bearing design. 


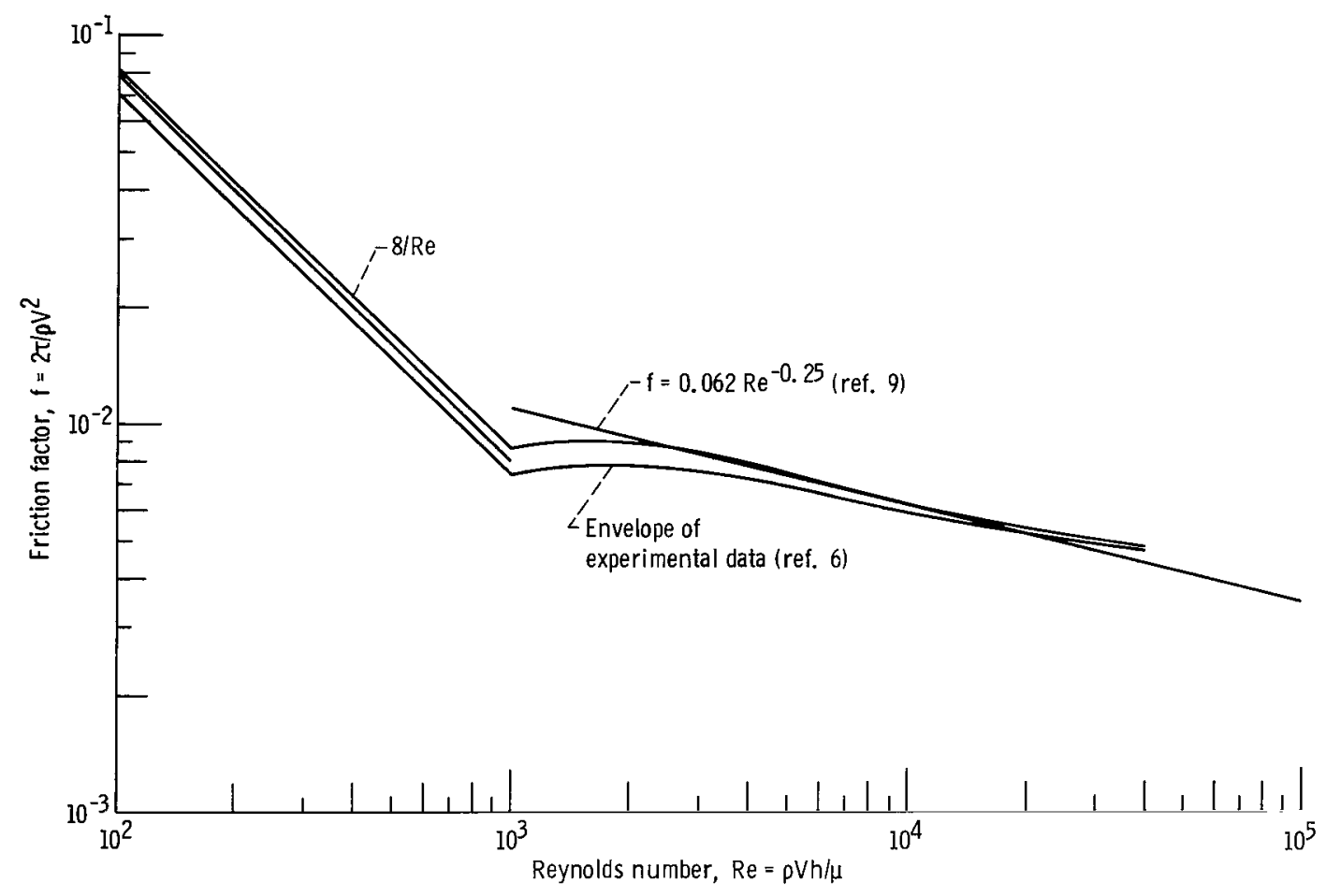

Figure 3. - Friction factor as a function of Reynolds number for hydrostatic journal bearing pockets. 


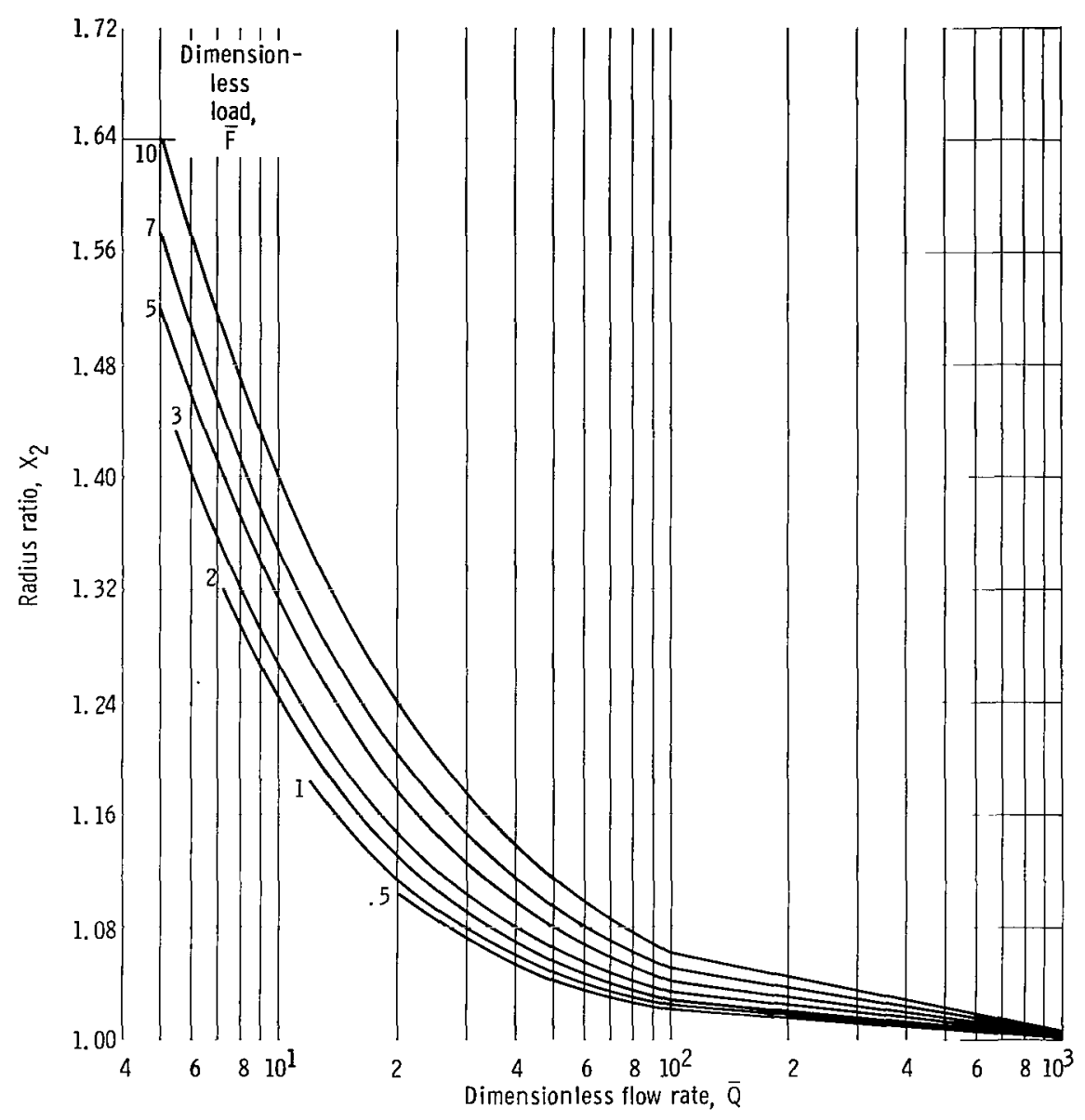

Figure 4. - Effect of flow rate on radius ratio $X_{2}$ for optimal bearing. Dimensionless laminar friction coefficient, 0. 


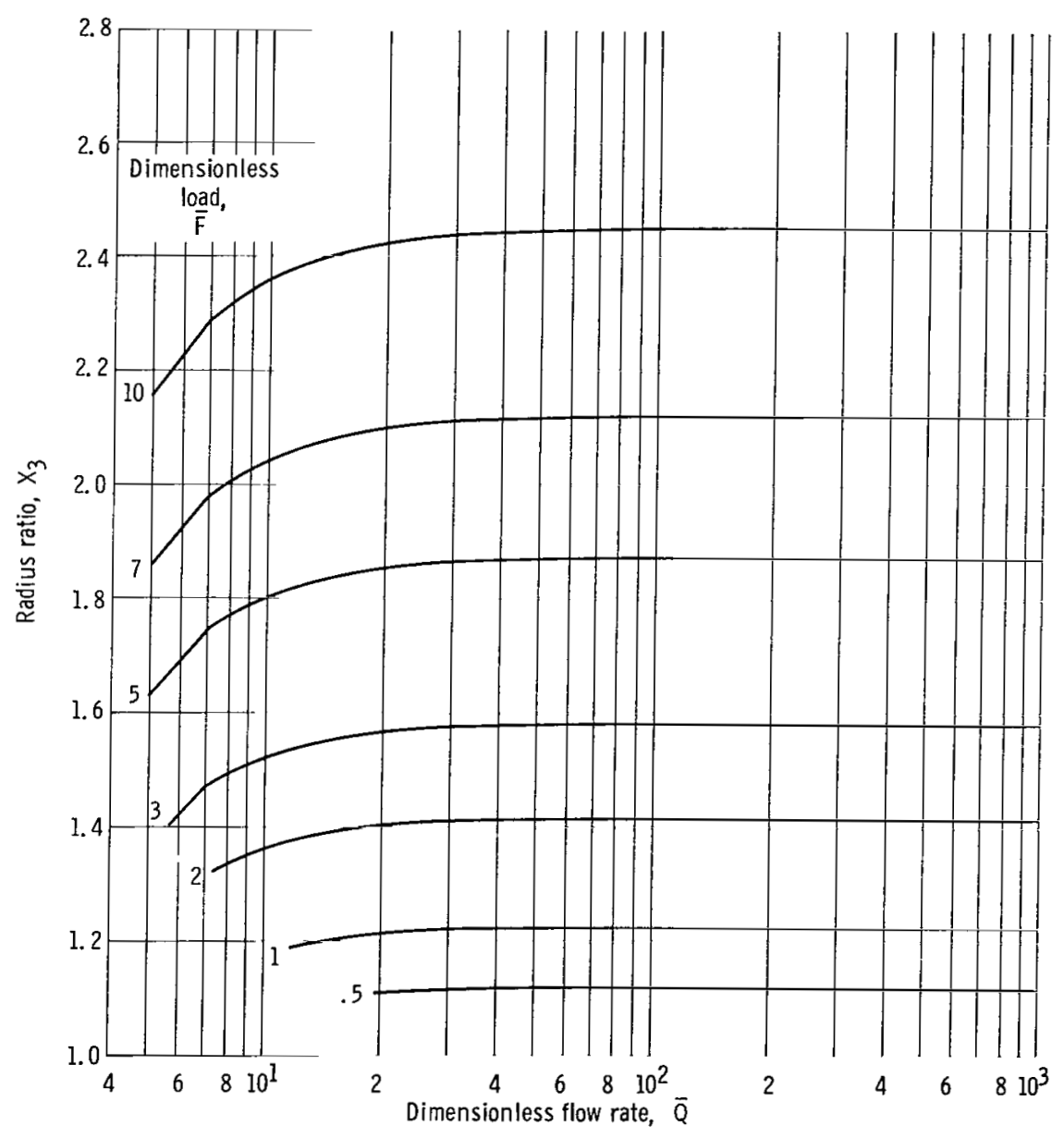

Figure 5. - Effect of flow rate on radius ratio $X_{3}$ for optimal bearing. Dimensionless laminar friction coefficient, 0 . 


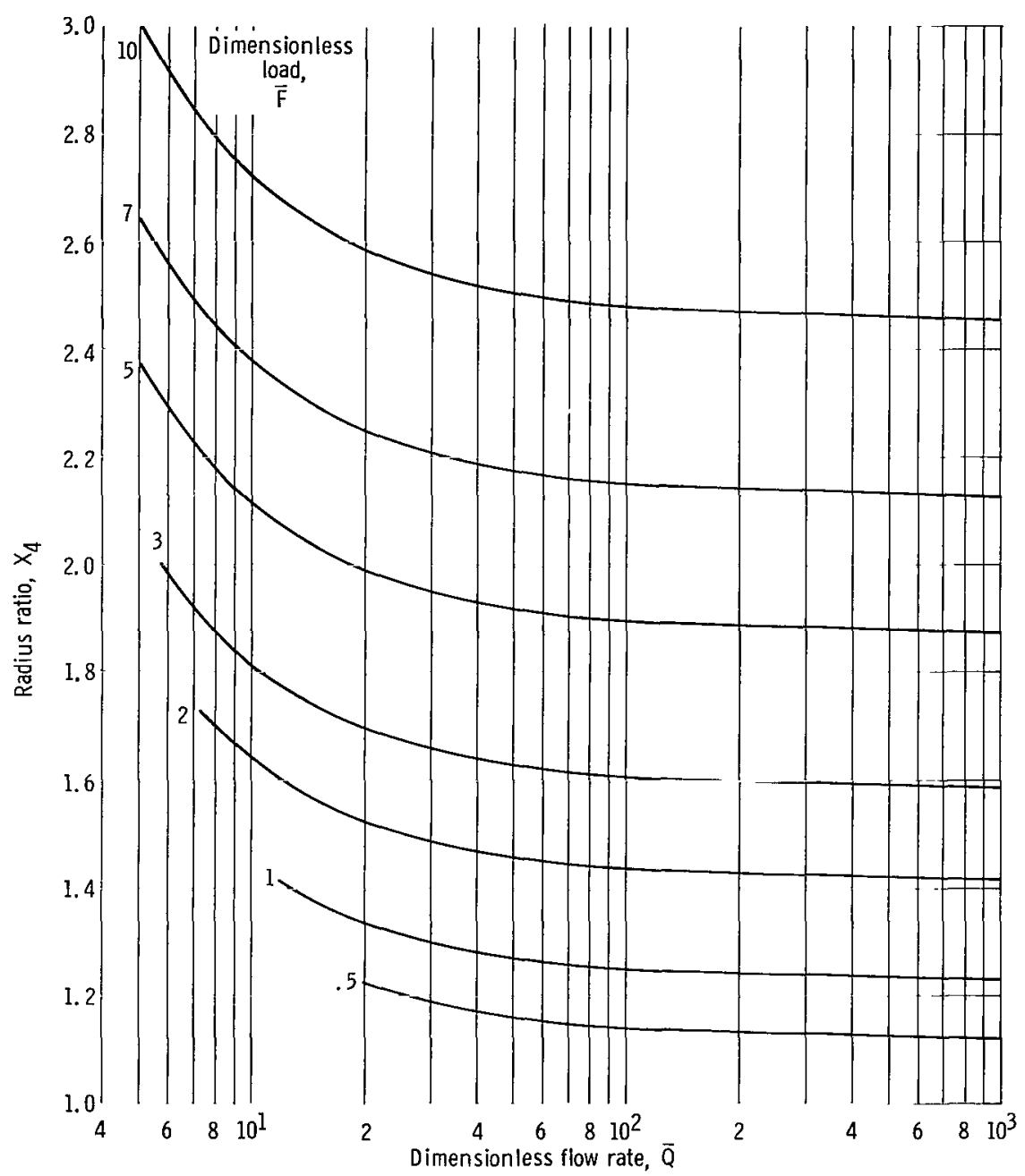

Figure 6. - Effect of flow rate on radius ratio $x_{4}$ for optimal bearing. Dimensionless laminar friction coefficient, 0 . 




Figure 7. - Effect of flow rate on friction torque for optimal bearing. Dimensionless laminar friction coefficient, 0 . 


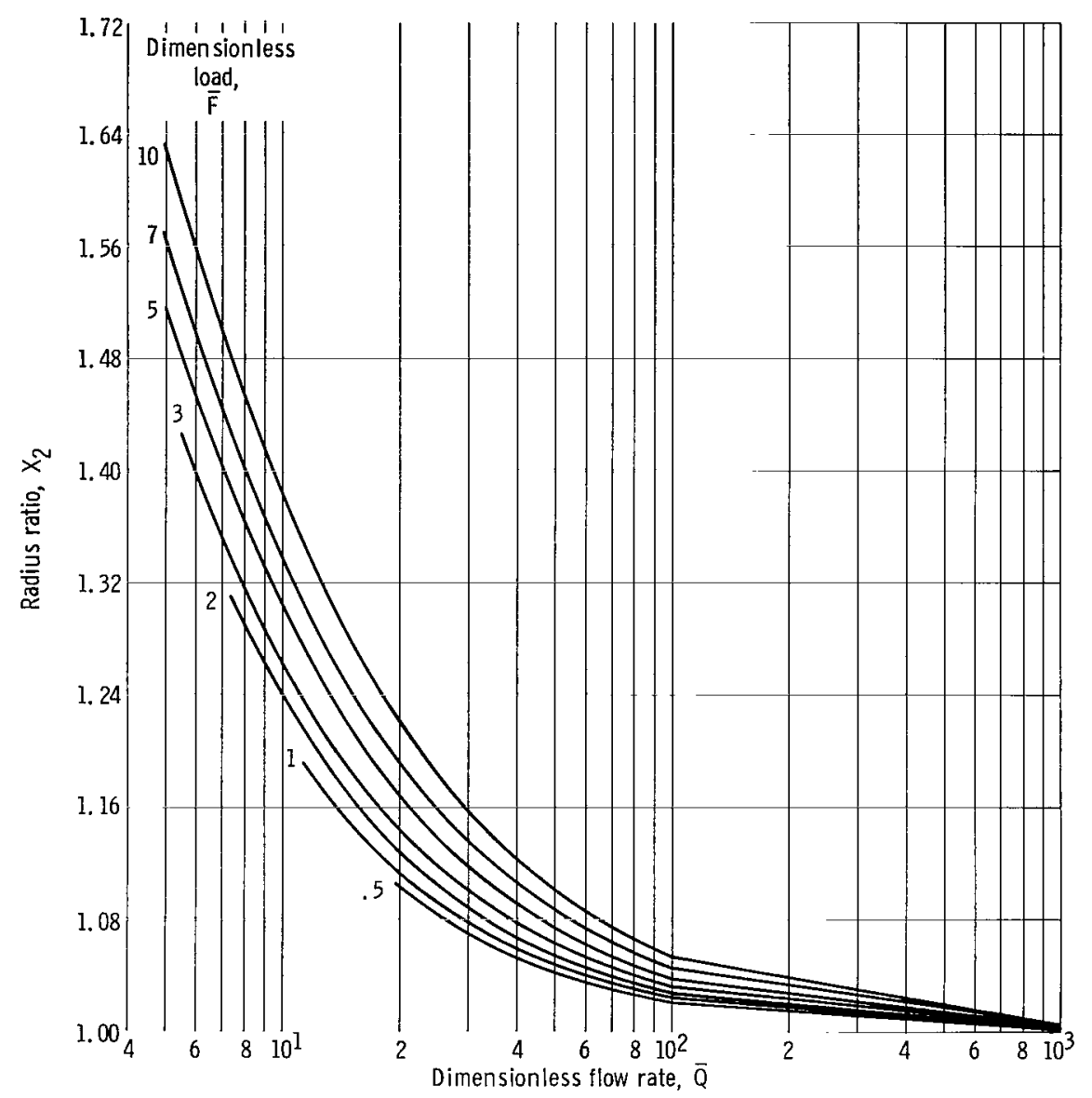

Figure 8. - Effect of flow rate on radius ratio $X_{2}$ for optimal bearing. Dimensionless laminar friction coefficient, 0.2. 


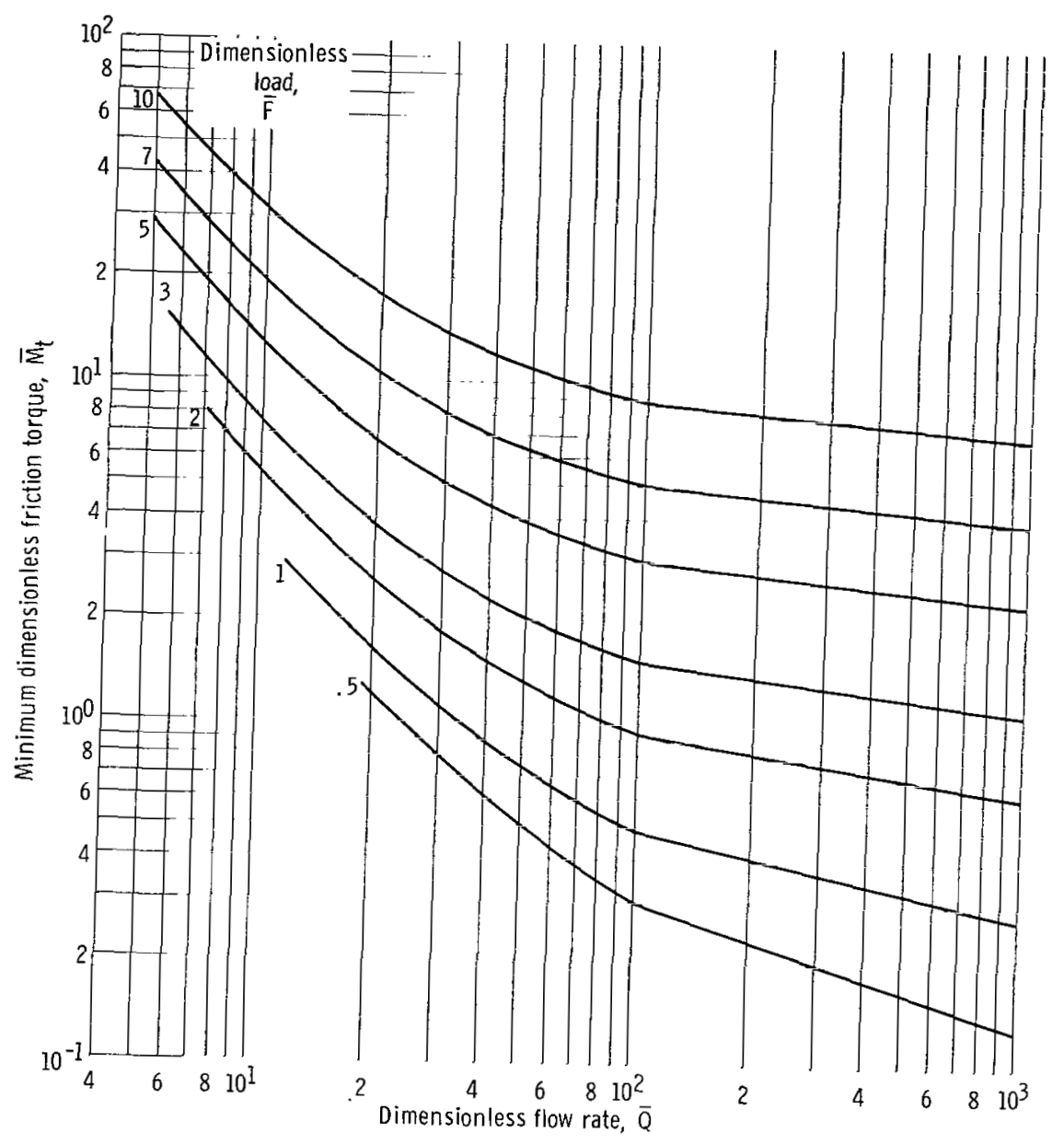

Figure 9. - Effect of flow rate on friction torque for optimal bearing. Dimensionless laminar friction coefficient, 0.2 


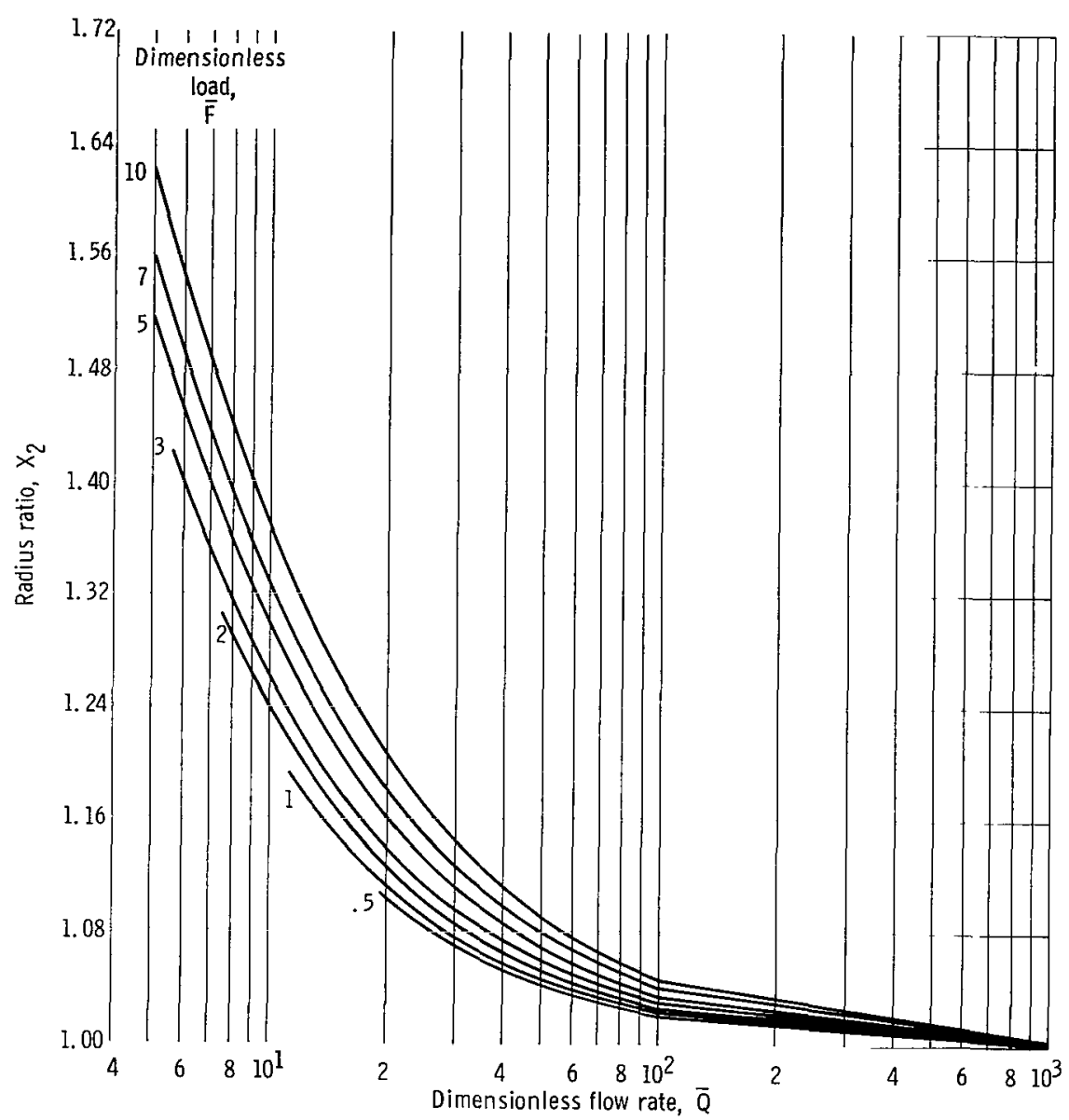

Figure 10. - Effect of flow rate on radius ratio $X_{2}$ for optimal bearing. Dimensionless laminar friction coefficient, 0.4 . 


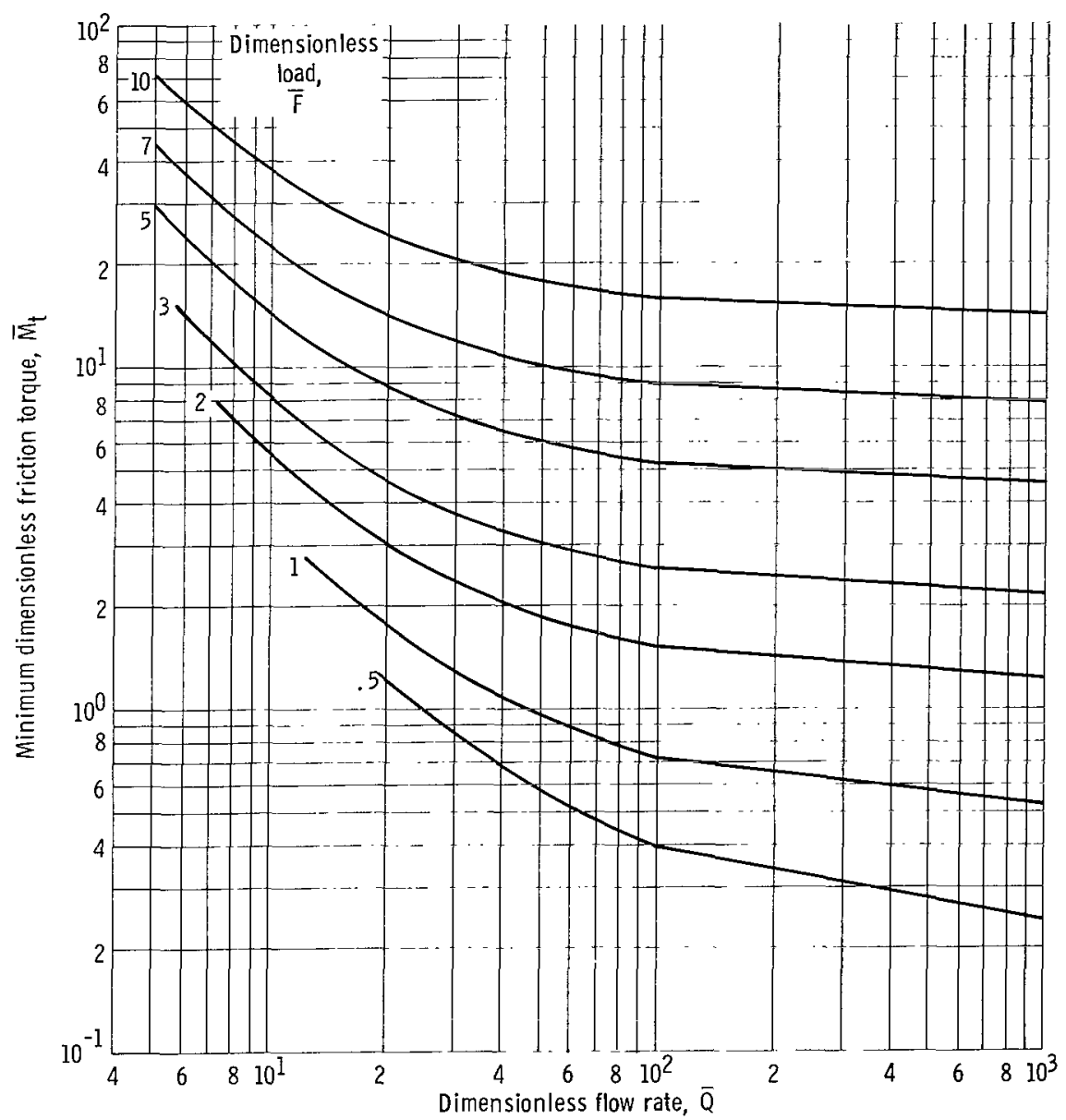

Figure 11. - Effect of flow rate on friction torque for optimal bearing. Dimensionless laminar friction coefficient, 0.4 . 


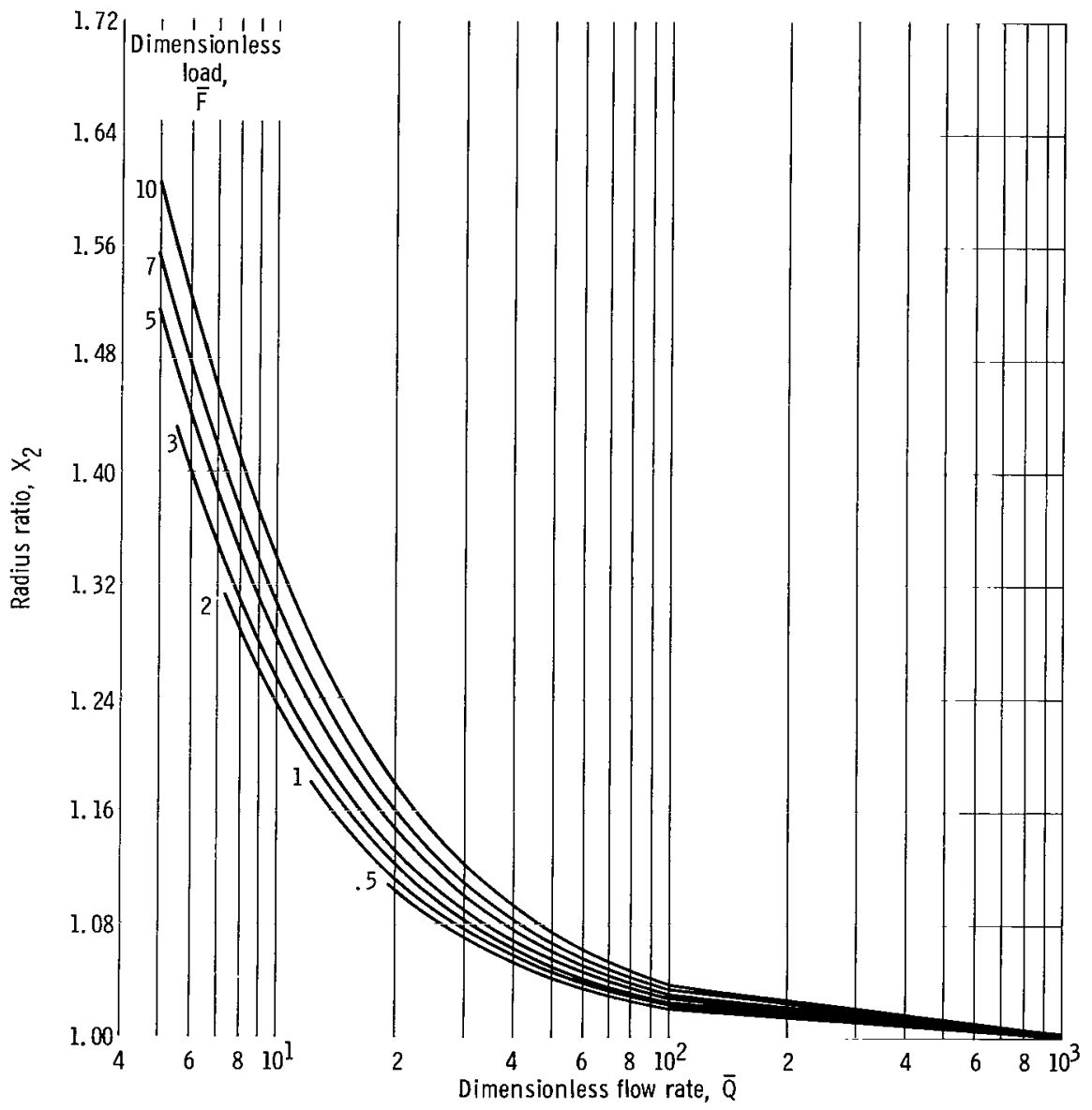

Figure 12. - Effect of flow rate on radius ratio $X_{2}$ for optimal bearing. Dimensionless laminar friction coefficient, 0.8 . 




Figure 13. - Effect of flow rate on friction torque for optimal bearing. Dimensioniess laminar friction coefficient, 0.8 . 


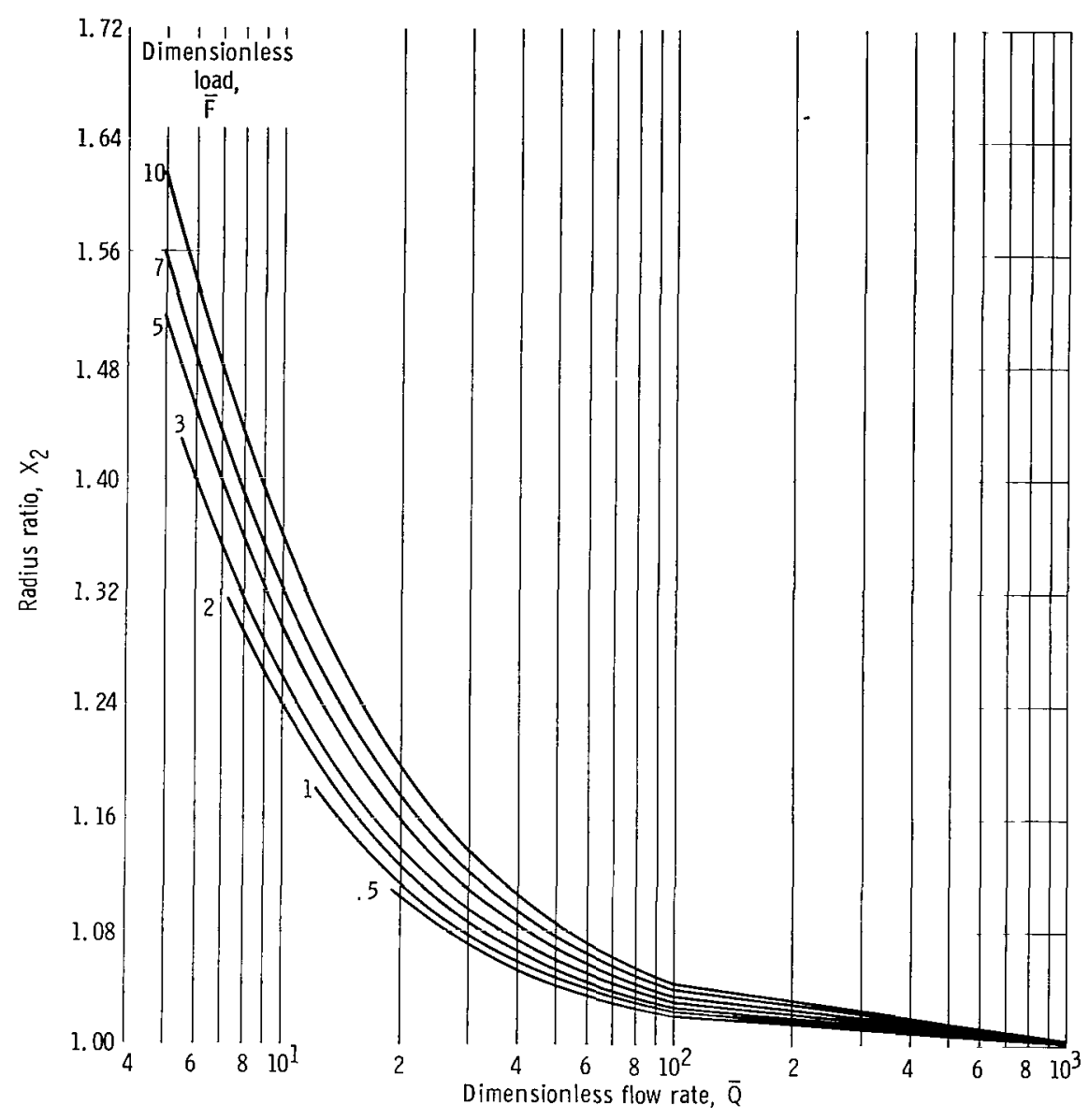

Figure 14. - Effect of flow rate on radius ratio $x_{2}$ for aptimal bearing. Dimensionless turbulent friction coefficient, 0.2 . 


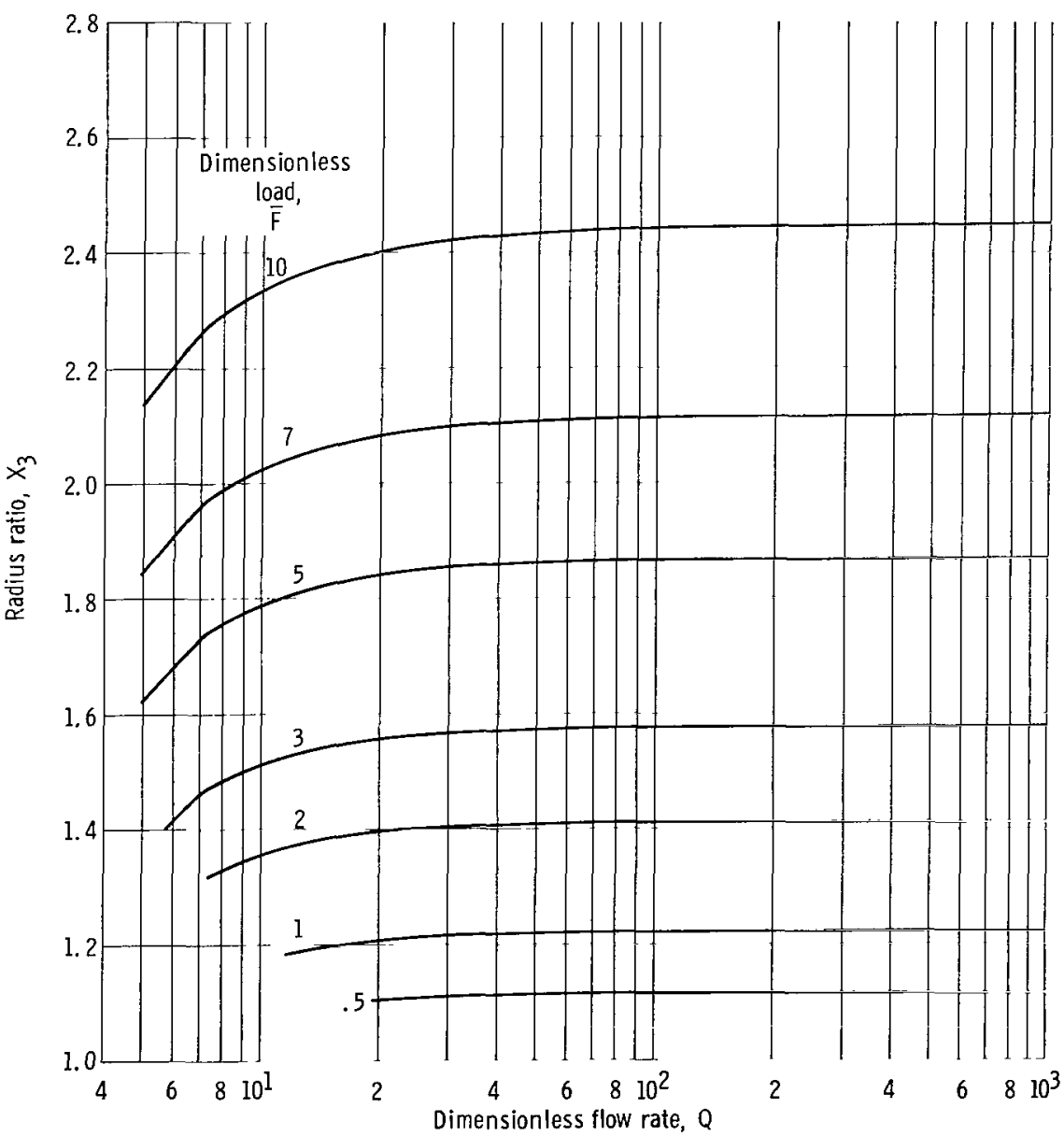

Figure 15. - Effect of flow rate on radius ratio $x_{3}$ for optimal bearing. Dimensionless turbulent flow coefficient, 0.2 . 


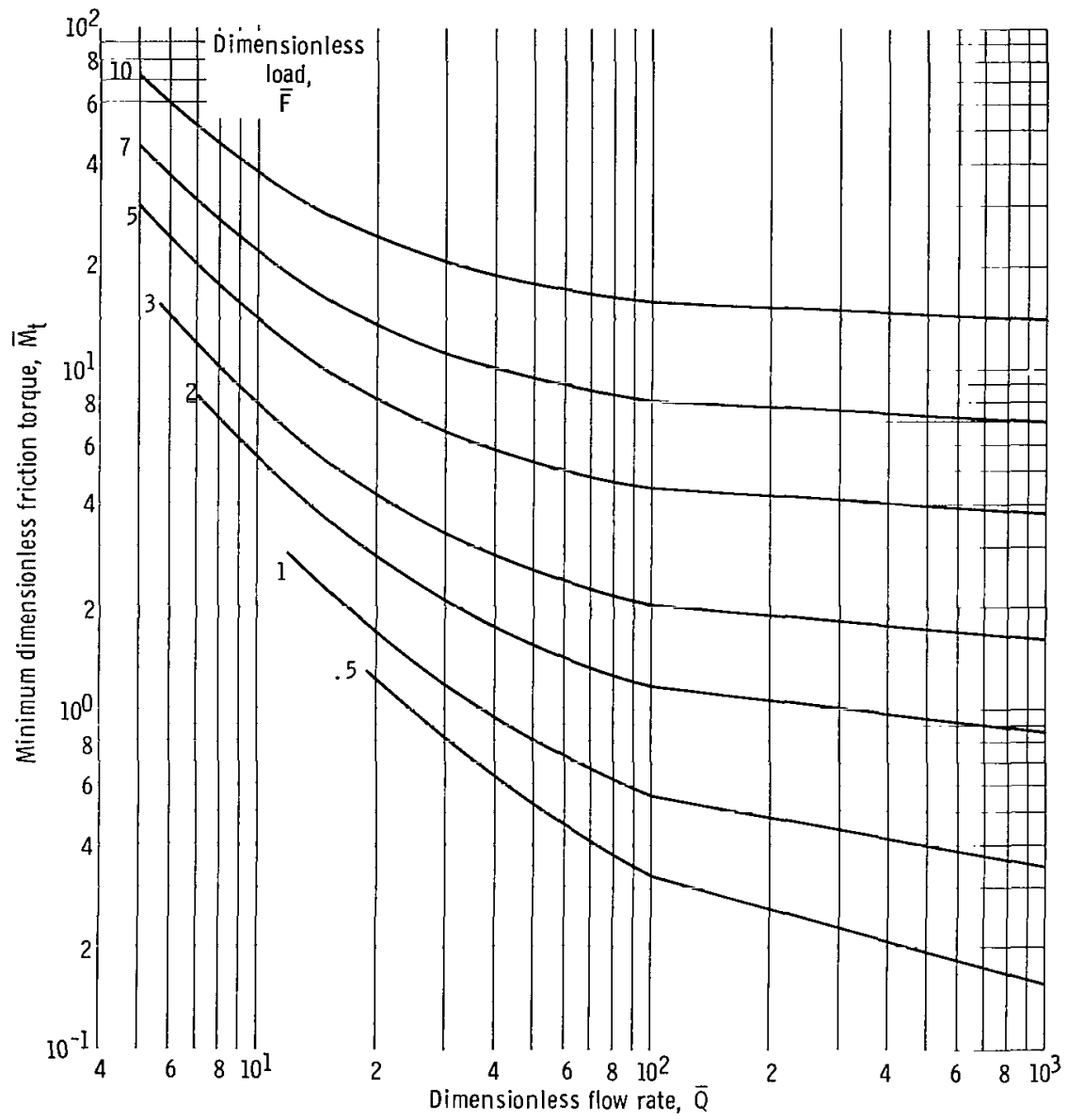

Figure 16. - Effect of flow rate on friction torque for optimal bearing. Dimensionless turbulent friction coefficient, 0.2 . 


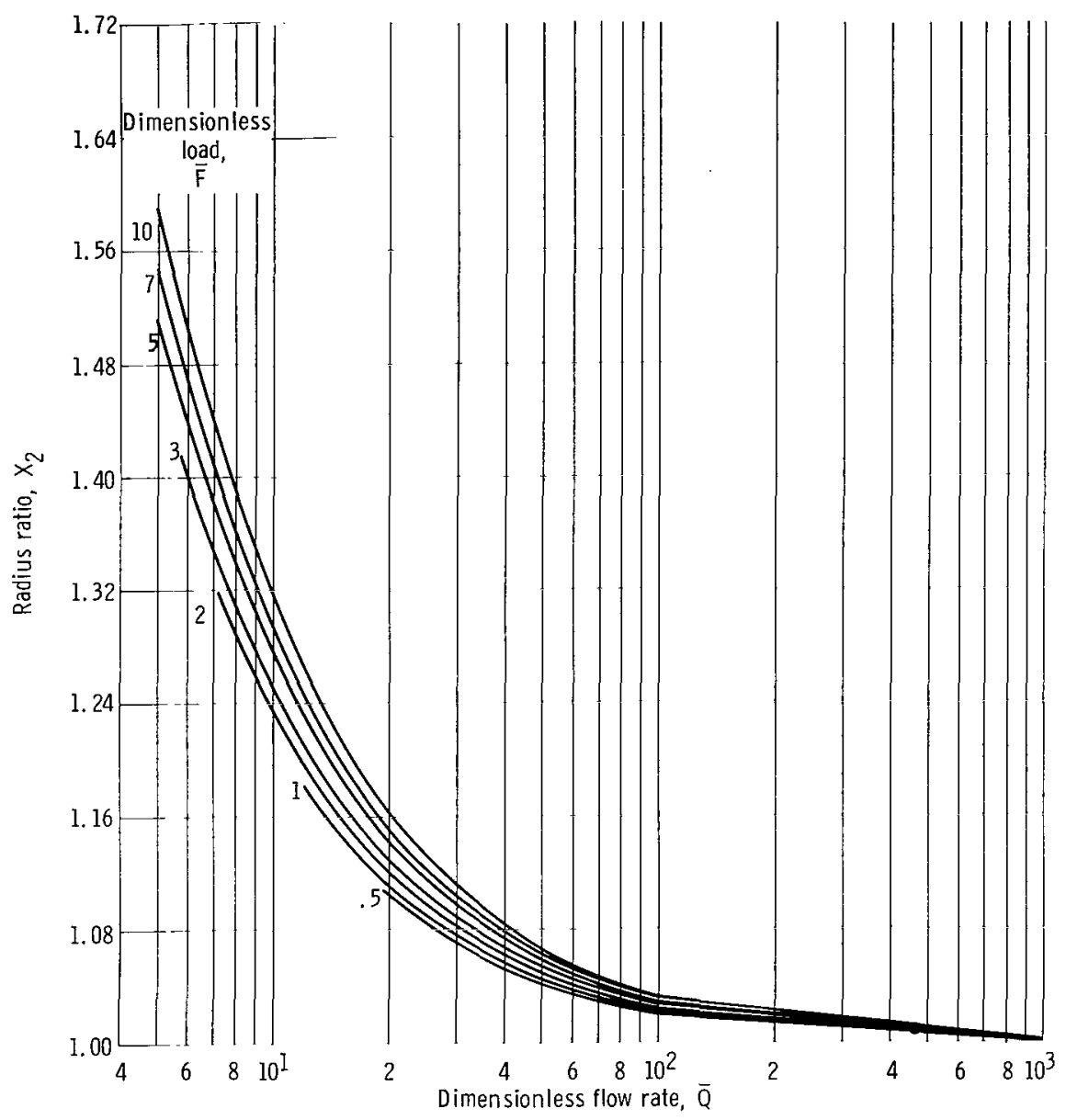

Figure 17. - Effect of flow rate on radius ratio $x_{2}$ for optimal bearing. Dimensionless turbulent friction coefficient, 0.4 . 


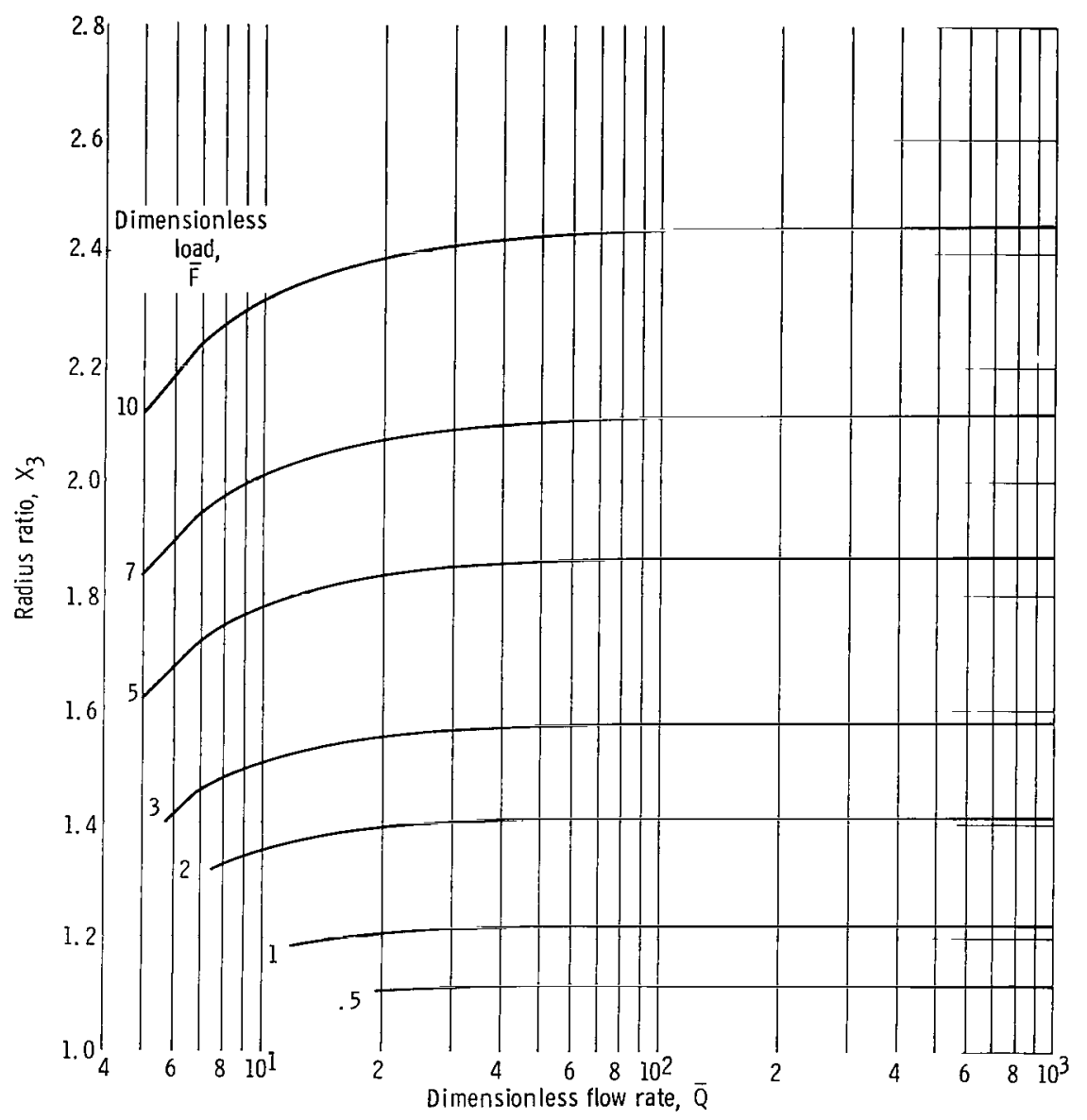

Figure 18. - Effect of flow rate on radius ratio $X_{3}$ for optimal bearing. Dimensionless turbulent friction coefficient, 0.4 . 


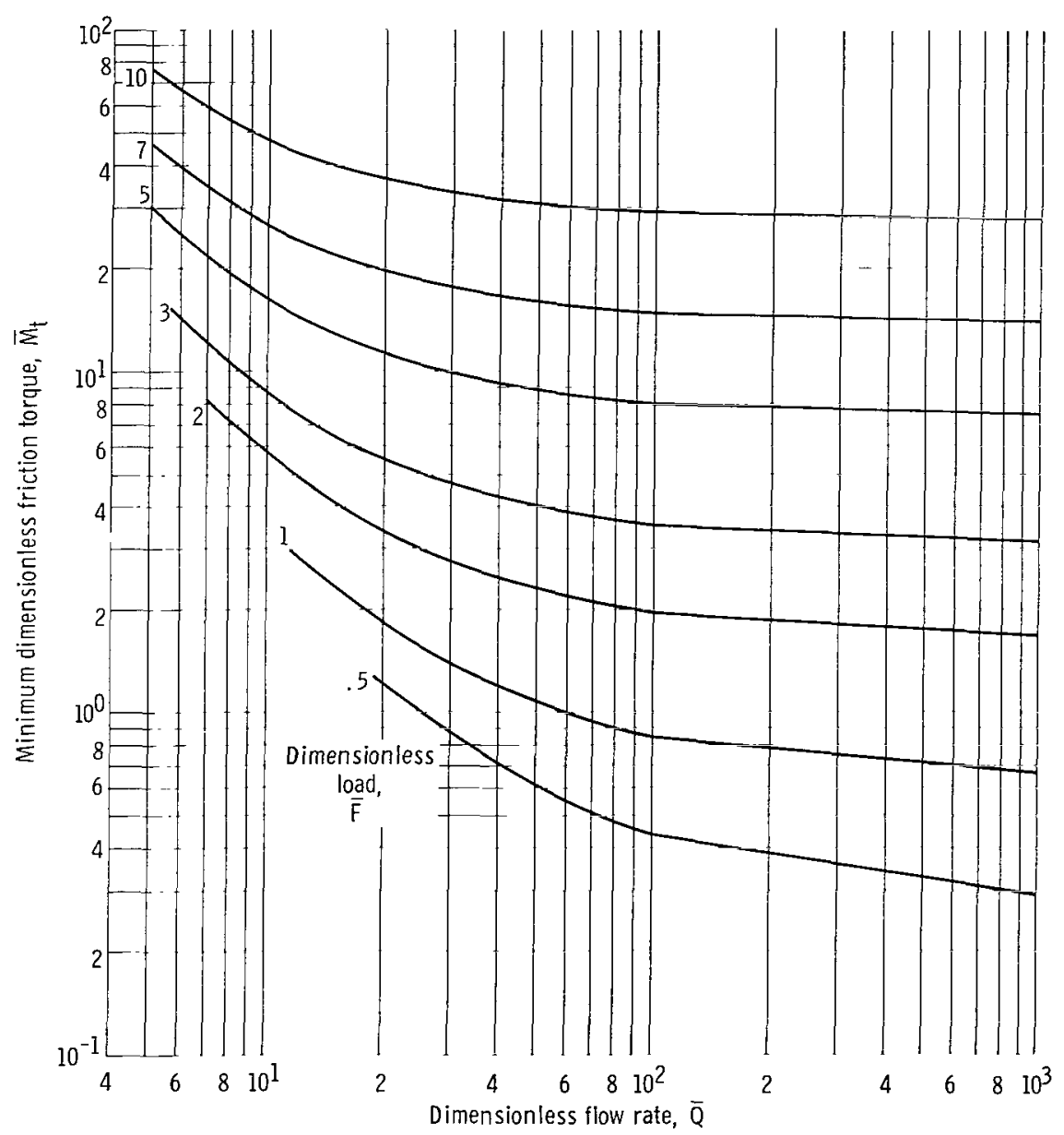

Figure 19. - Effeci of flow rate on friction torque for optimal bearing. Dimensionless turbulent friction coefficient, 0.4 . 


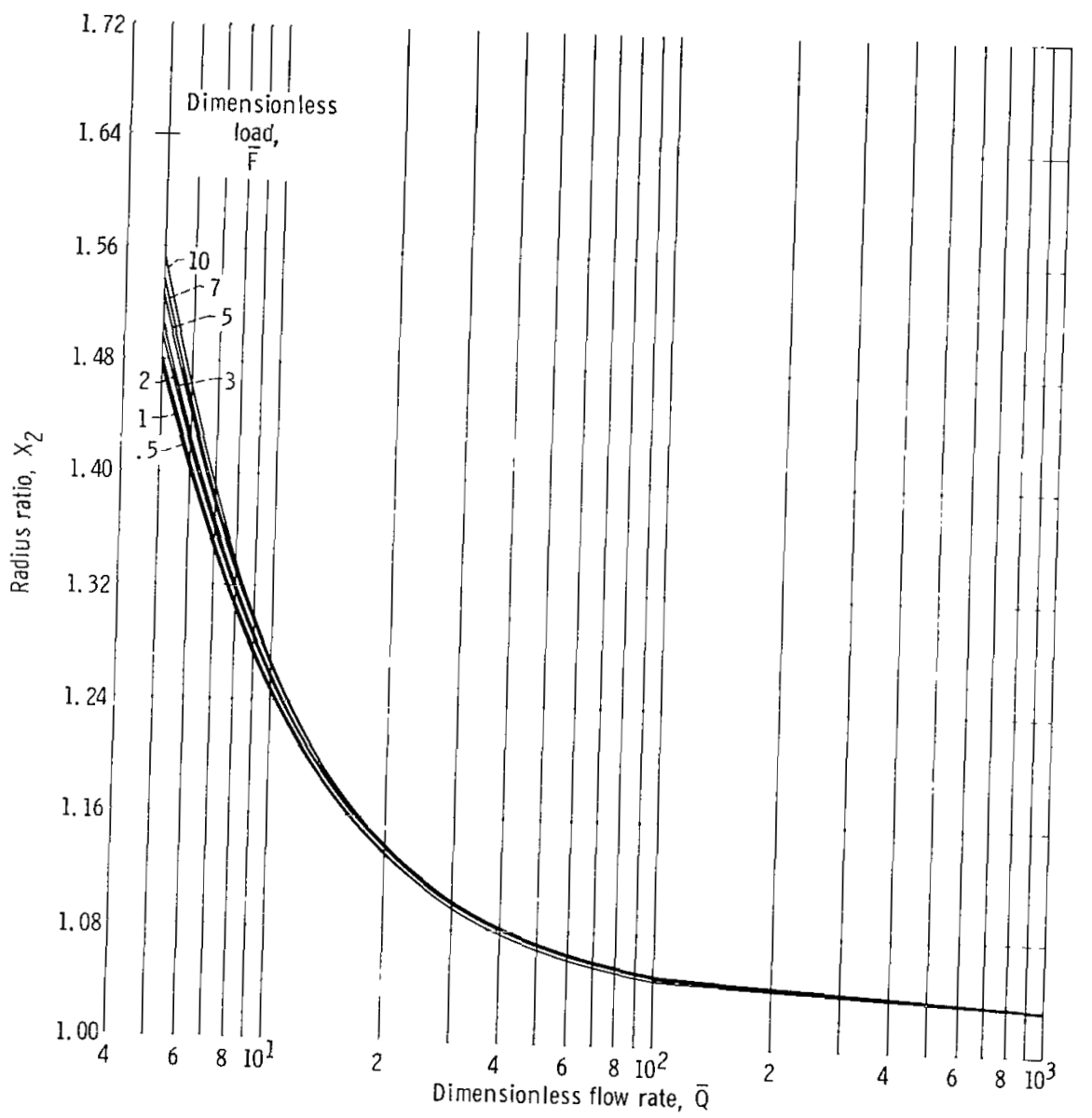

Figure 20 . Effect of flow rate on radius ratio $x_{2}$ for optimal bearing. Dimensionless tur bulent friction coefficient, 0.8 . 




Figure 21. - Effect of flow rate on radius ratio $X_{3}$ for optimal bearing. Dimensionless turbulent friction coefficient, 0.8 .

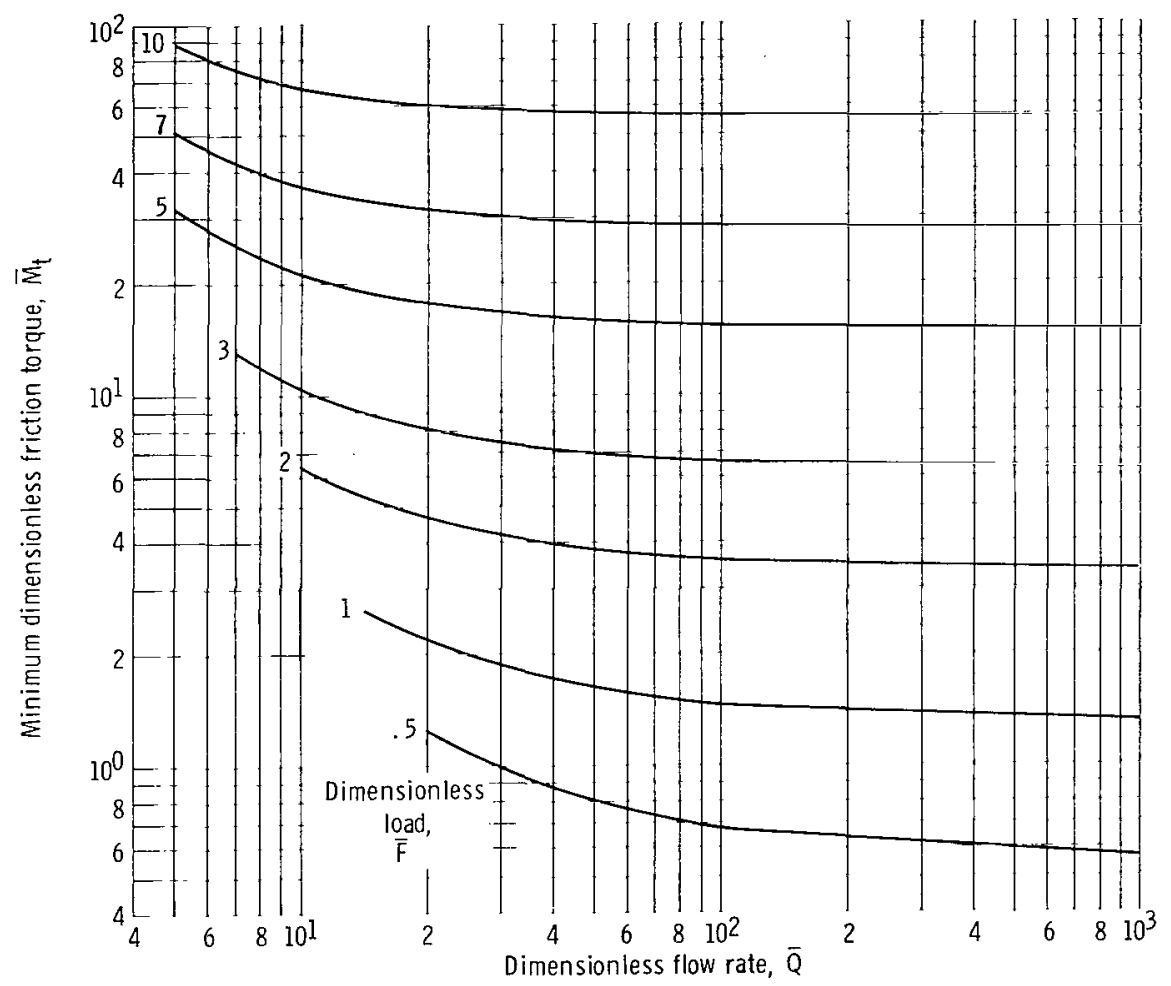

Figure 22. - Effect of flow rate on friction torque for optimal bearing. Dimensionless turbulent friction coefficient, 0.8 . 
$10 U 00140$

51 3DS

7116600903

AIR FORCE WEAPONS LABORATORY /WLOL/

KIRTLAND AFB, NEW MEXICO 87117

"The aeronautical and space activities of the United States shall be conducted so as to contribute . . to the expansion of buman knowledge of phenomena in the atmosphere and space. The Administration shall provide for the widest practicable and appropriate dissemination of information concerning its activities and the results thereof."

- National Aeronautics and Space ACt of 1958

\section{NASA SCIENTIFIC AND TECHNICAL PUBLICATIONS}

TECHNICAL REPORTS: Scientific and technical information considered important, complete, and a lasting contribution to existing knowledge.

TECHNICAL NOTES: Information less broad in scope but nevertheless of importance as a contribution to existing knowledge.

TECHNICAL MEMORANDUMS:

Information receiving limited distribution because of preliminary data, security classification, or other reasons.

CONTRACTOR REPORTS: Scientific and technical information generated under a NASA contract or grant and considered an important contribution to existing knowledge.
TECHNICAL TRANSLATIONS: Information published in a foreign language considered to merit NASA distribution in English.

SPECIAL PUBLICATIONS: Information derived from or of value to NASA activities. Publications include conference proceedings, monographs, data compilations, handbooks, sourcebooks, and special bibliographies.

TECHNOLOGY UTILIZATION PUBLICATIONS: Information on technology used by NASA that may be of particular interest in commercial and other non-aerospace applications. Publications include Tech Briefs, Technology Utilization Reports and Technology Surveys.

Details on the avallability of these publications may be obtained from:

SCIENTIFIC AND TECHNICAL INFORMATION OFFICE

NATIONAL AERONAUTICS AND SPACE ADMINISTRATION Washington, D.C. 20546 